\title{
Study on the Ectoparasites and Haemoparasites of Domestic Rats in Parts of Akure South Local Government Area of Ondo State
}

\author{
Dada, E. O. \\ Department of Microbiology, The Federal University of Technology, P.M.B 704, Akure, Nigeria. \\ dadaoluyemi5@gmail.com
}

\begin{abstract}
Study on the prevalence of ectoparasites and haemoparasites of domestic rats in parts of Akure South Local Government was carried out from July to September 2015. The rodents were trapped using locally fabricated traps. Body brushing technique was used to collect their ectoparasites. Blood samples from each rat were collected and examine using standard biological techniques. Specie of rodents captured was the cosmopolitan commensal rodents: Rattus rattus, Rattus norvegicus, Mus musculus, and Mastomys natalensis. The ectoparasites collected from the rats are species of ticks: Haemaphysalis spp, Rhipicephalus sanguineus, fleas: Xenopsylla cheopis, mites: Dermanyssus spp and lice: Polyplax spp. The total ectoparasite prevalence was $44 \%$ with tick (Haemaphysalis spp) being the most prevalent (33.3\%) and (Xenopsylla cheopis) being the least prevalent (7.4\%). High prevalence was found in Apatapiti (16\%) than in Aba and Akindeko hostel with prevalence of (12\%), and Road block (8\%), Jibowu hostel have the least prevalence (4\%). The haemoparasites identified were Plasmodium and Trypanasoma species with prevalence of $12 \%$ and $4 \%$ respectively. The overall rodent ectoparasite index of 1.08 signifies a potential risk to human health. The public health implications of these findings require community-wide rodents control strategies with strong emphasis on community participation in order to prevent rapid spread of rodent population.
\end{abstract}

Keywords: Study, Prevalence, Ectoparasites, Haemoparasites, Domestic, Rats.

\section{INTRODUCTION}

Ectoparasites inhabit the skin or outgrowths of the skin of their hosts. Many of these ectoparasites (mostly lice) are host specific, while others (most ticks) parasitizes wide range of hosts. Most ectoparasites are invertebrates and are arthropods, insects and arachnids which typically parasitize terrestrial domestic animals. Some ectoparasites are also known to be vectors of pathogen which the parasites typically transmit to the host while feeding or defecating (Davis et al. 2005). Haemoparasites (blood parasites) are those parasites which pass most of their lives usually in the vascular system of vertebrates and mammals. Some of these are Babesia, Theileria, Trypanosoma, Plasmodium species and others. (Battersby et al.2002).

Rats (superfamily Muroidea) are various medium-sized, long-tailed rodents. True rats are members of the genus Rattus. The most important of the genus are the black rat, Rattus rattus, and the brown rats, Rattus norvegicus (Meerburg et al., 2009). Both black rats and brown rats by their very nature and design, make excellent vehicles for harbouring and rapidly transporting diseases. Rodents are well adapted to living with or in close proximity to humans hence man are quite vulnerable to the potential spread of any pathogens carried by rodents. Even without parasites, rodents can directly transmit deadly germs excreted in their urine and feces. In addition, rodents shed their hairs daily and lose an entire coat twice a year. In this way, millions of rodent hairs and hair fragments, possibly containing pathogens, are also deposited into our environment (Barnett, 2002).

This study was carried out to estimate the distribution of ectoparasite infestations of domestic rodents in the study areas and to determine the prevalence of haemoparasites in the rodents.

\section{Materials and Methodology}

\subsection{Study Areas}

A survey on the ectoparasites and haemoparasites of domestic rats was carried out in some parts of Akure South Local Government and area Ondo State. Orita-Obele along Ijare road is a densely populated area.Apart from the residential houses, most drainage is blocked with piles of rubbish, and 
there are markets, shops and commercial business centres. Areas around "The Federal University of Technology Akure (FUTA)" consist of FUTA Southgate, Apatapiti layout, Alaba layout, Jibowu hostel and Akindeko hostel. The majority of the people living in these areas are mostly students. Apart from FUTA students hostels (Jibowu hostel and Akindeko hostel), all the areas are densely populated and majority of the inhabitants engage in petty trading around the houses. Most students' residential houses built by local landlords are at low rental rates, poorly managed, built close to bushes; with several cracks on the walls and greater proportion have pit latrines. All these factors tend to attract rodents into the residential apartments, local markets and commercial business centres.

\subsection{Rat Capturing and Classification}

The study was carried out using twenty five rats (black and brown). The method of Soulsby (1982) was adopted by using locally made metal traps to capture the rats. Traps were baited with fried fish to serve as attractants were set and placed in kitchen and corridors in the night. The rats were transported to the laboratory in perforated metal boxes to provide good ventilation and allow conducive environment for the animals in transit. Rats were identified and classified to specie level using the method of (Meerburg et al., 2009).

\subsection{Survey for Ectoparasites}

The ectoparasite study was carried out using the method of Soulsby (1982).Captured rodents were subjected to euthanasia under diethyl ether anesthesia. The unconscious rats were placed on a clean white tile. Starting from the head to the neck, trunk and the tail, ectoparasites were dislodged from the rats body by brushing with the aid of hand brush onto cotton wool soaked in formalin. Visible ectoparasites such as ticks that could easily be removed without brushing were removed with a pair of forceps. The ectoparasites recovered were preserved in specimen bottles containing $70 \%$ alcohol, the parasites were sorted and transferred to the microscope slide for identification.

\subsection{Haematological Examination for Haemoparasites}

Blood samples were collected from the rodents by cardiac puncture into EDTA bottles from the rodents. Thick and thin blood smears were prepared from each blood sample on grease free slides. Slides were stained in a $10 \%$ Giemsa staining solution for 20 minutes then flushed with water to remove excess stain and allowed to air dry completely before fixation in pure methanol for one minute and then dried again (Olubunmi 2013).The blood smears were examined under the oil immersion objective lens and the haemoparasites were identified using the information and structures on parasitized red blood cells (WHO 1991).

\section{Data Analysis}

Data were analysed using chi-square analysis to test significant difference in species distribution in the study locations, Estimation of rodent ectoparasite infestation was done by employing simple percentage and statistical analysis of Bush et al.,(1997 ) in Okeke et al (2013) where the prevalence, mean abundance and mean intensity of the parasites were tested for and expressed as follows;

Prevalence $(\mathrm{N})=\mathrm{N}_{1} / \mathrm{N}_{2} * 100 / 1$, Where $\mathrm{N}=$ Percentage prevalence, $\mathrm{N}_{1}=$ Number of host infected, $\mathrm{N}_{2}$ $=$ Total number of hosts examined for the parasite.

Mean abundance (MA) is the ratio of the total number of a particular parasite species in a particular host to the total number of the hosts examined.

Mean intensity (Mi) is the ratio of total number of a particular species found in a sample to the number of hosts infected.

The number of ticks, fleas, lice and mites collected from the rat examined divided by the total number of rats examined gives the ectoparsite index.

Rodent ectoparasite index $=$ Number of ectoparasites collected from examined rats

$$
\text { Total number of rats examined }
$$

\section{Results}

Table 1 show that overall prevalence of ectoparsite infestation was $80 \%$. Highest ectoparasite infestation rate (20\%) was respectively observed in Aba and Apatapiti areas, Followed by Road block and Akindeko hostel with $16 \%$ while the lowest infestation rate was found in Jibowu hostel (8\%). The ectoparasites encountered in this study are ticks, fleas, lice and mites (Table 2). Tick infestation 
on the rats was high (16\% and 12\%) in Apatapiti and Akindeko hostel areas respectively. Fleas and mites infestation of the rats captured in all the areas was low and ranged from $4 \%$ to $8 \%$, ectoparasite index was 0.52 for tick, 0.32 for lice, 0.16 for mites and 0.08 for fleas. Table 3 show that Rattus rattus was highly prevalence (36\%), followed by Rattus norvegicus (28\%), then Mus musculus (12\%) and the least prevalence of $4 \%$ for Mastomys natalensis.

Overall prevalence (Table 4) of ectoparasite infestation was high (44.00\%) in Rattus rattus, followed by $40.00 \%$ in Rattus norvegicus, then $20.00 \%$ in Mus musculus and the least was $4.00 \%$ in Mastomys natalensis. Total number of tick infestation in all the infested rats was 13, while the number of lice was 8 , mites and fleas were 4and 2 in number respectively. The prevalence of tick infestation was $24 \%$ in Rattus rattus, and $16 \%$ in Rattus norvegicus. In Rattus rattus and Rattus norvegicus, the observed prevalence for lice was $16 \%$ and $12 \%$ respectively.

All the ectoparasites were found to infest Rattus rattus and Mus musculus while all the ectoparasites except fleas were found in Rattus rattus, only 1 tick was found in Mastomys natalensis with a prevalence of $4 \%$. The respective ectoparasite specie that was isolated from the rodents and their respective prevalence is shown in table 5. Prevalence of $33.33 \%$ was observed for Haemaphysalis spp, and then Polyplax spp (29.63\%), Dermanyssus spp (14.81\%) and the least was $7.40 \%$ for Xenopsylla cheopis.

Haemoparasite prevalence in Table 6, show that only three (3) of the twenty five (25) rats were found infected with Plasmodium spp, representing a prevalence of $12 \%$ and one (1) rat was infected with Trypanosoma spp, representing a prevalence of $4 \%$.

\section{DisCuSSION}

Ectoparasite species of lice, fleas, ticks, and mites encountered in this study are those that have been previously reported from the Northern part of Nigeria (Mbanong et.al. 2002). Tick sespecially the Haemaphysalis spp were the most prevalent ectoparasites encountered in this study. Previous studies of Stojcevic et.al (2004), Mbanong, et.al. (2002) had reported lice (Polyplax species) to be more prevalent than ticks which differ from this present studies. The high prevalence of ticks than fleas in this study may be due to their adhesive mechanisms to the host while the low prevalence of the fleas could be attributed to their flying ability to escape from their host. The haemoparasites (Plasmodium and Trypanosome spp) observed in the blood cell of the rodents is expected. These genera of haemoparasites are those commonly found associated with rodents (Opara and Fagbemi, 2008).

Rodents species (Rattus rattus, Rattus norvegicus, Mus musculus and Mastomys natalensis) captured in this study belong to the cosmopolitan commensal rodents that are often found in close association with people in dense settlements. The studies of M banonget.al, (2002), Mafiana et.al, (1997) and Olaseha et.al., (1994) showed that these species seem to be widely distributed in Nigeria. The importance of adequate housing and sanitation for the maintenance of health has long been a topic of scientific and public health policy discussion. It is therefore established in this study that crowded, unsanitary, and dilapidated housing conditions exacerbate rodent infestation in study areas. Houses with disrepair indicators and poor sanitary conditions accounted for higher rodent captured when compared with those without evidence of disrepair.

\section{Conclusion}

This study has shown that infestation of rodents by ectoparasites is of serious zoonotic importance Rodent and rodent-borne parasites may become more serious in human population, zoonotic transmission of these rat-borne parasites are exacerbated in communities where standards of environmental and personal hygiene are not maintained.Lassa fever, a serious rat borne disease first discovered in Nigeria in 1969, is now endemic in the whole West Africa sub region because the rodent species (Mastomys also known as multimalmate rat) which carry the virus are spreading throughout the region as reported by (Bonner et.al., 2007). The four species of rodents documented in this study and their ectoparasite fauna are of veterinary and medical importance. According to Piniet.al (2003), their involvement in the epidemiology of new and emerging infectious diseases of epidemic importance cannot be put aside. This finding is therefore a critical step to estimating and assessing the status of rodent infestation in the study area. In view of this, community-wide rodents control strategies with strong emphasis on community participation must be employed to prevent rapid spread of rodent population. 
Dada, E. O.

Table1. Prevalence of ectoparasite infestation related to location in captured rodents

\begin{tabular}{|c|c|c|}
\hline Study location & Number of rodents captured & Number of rodents infested \& Infection rate (\%) \\
\hline Aba & 6 & $5(20.00)$ \\
\hline Apatapiti & 6 & $5(20.00)$ \\
\hline Road block & 5 & $4(16.00)$ \\
\hline Akindeko hostel & 5 & $4(16.00)$ \\
\hline Jibowu hostel & 3 & $2(8.00)$ \\
\hline Total & 25 & $20(80.00)$ \\
\hline
\end{tabular}

Table2. Prevalence of ectoparasite infestation in each study area

\begin{tabular}{|l|c|l|l|l|c|}
\hline Location & $\begin{array}{l}\text { Number of tick } \\
\text { and Prevalence } \\
(\%)\end{array}$ & $\begin{array}{l}\text { Number of fleas } \\
\text { and prevalence } \\
(\%)\end{array}$ & $\begin{array}{l}\text { Number of lice } \\
\text { and prevalence } \\
(\%)\end{array}$ & $\begin{array}{l}\text { Number of mites } \\
\text { and prevalence } \\
(\%)\end{array}$ & $\begin{array}{l}\text { Total } \\
\text { ectoparasite }\end{array}$ \\
\hline Aba & $3(12.00)$ & $-(0.00)$ & $3(12.00)$ & $1(4.00)$ & 7 \\
\hline Apatapiti & $4(16.00)$ & $1(4.00)$ & $2(8.00)$ & $1(4.00)$ & 8 \\
\hline Road block & $2(8.00)$ & $-(0.00)$ & $-(0.00)$ & $1(4.00)$ & 3 \\
\hline Akindeko hostel & $3(12.00)$ & $1(4.00)$ & $2(8.00)$ & $-(0.00)$ & 6 \\
\hline Jibowu hostel & $1(4.00)$ & $-(0.00)$ & $1(4.00)$ & $1(4.00)$ & 3 \\
\hline \multicolumn{7}{|c|}{ Ectoparasite } & $\mathbf{0 . 1 6}$ \\
\hline Index $\mathbf{0 . 5 2}$
\end{tabular}

Table3. Prevalence related to spices of rodents

\begin{tabular}{|l|c|c|}
\hline Rat species & Number rat captured & Number infested \& prevalence (\%) \\
\hline Rattus rattus & 11 & $9(36.00)$ \\
\hline Mastomys natalensis & 2 & $1(4.00)$ \\
\hline Rattus norvegicus & 8 & $7(28.00)$ \\
\hline Mus musculus & 4 & $3(12.00)$ \\
\hline Total & $\mathbf{2 5}$ & $\mathbf{2 0}(\mathbf{8 0 . 0 0 )}$ \\
\hline
\end{tabular}

Table4. Prevalence of ectoparasites related to species of rodents

\begin{tabular}{|c|c|c|c|c|c|}
\hline Rat species & $\begin{array}{c}\text { Number of } \\
\text { tick \& } \\
\text { prevalence } \\
(\boldsymbol{\%})\end{array}$ & $\begin{array}{c}\text { Number of } \\
\text { fleas \& } \\
\text { prevalence } \\
(\boldsymbol{\%})\end{array}$ & $\begin{array}{c}\text { Number of } \\
\text { lice \& } \\
\text { prevalence } \\
(\boldsymbol{\%})\end{array}$ & $\begin{array}{c}\text { Number of } \\
\text { mites \& } \\
\text { prevalence (\%) }\end{array}$ & $\begin{array}{c}\text { Total number of } \\
\text { ectoparasite } \\
\text { \& prevalence (\%) }\end{array}$ \\
\hline Rattus rattus & $6(24.00)$ & $-(0.00)$ & $4(16.00)$ & $1(4.00)$ & $11(44.00)$ \\
\hline Mastomys natalensis & $1(4.00)$ & $-(0.00)$ & $-(0.00)$ & $-(0.00)$ & $1(4.00)$ \\
\hline Rattus norvegicus & $4(16.00)$ & $1(4.00)$ & $3(12.00)$ & $2 .(8.00)$ & $10(40.00)$ \\
\hline Mus musculus & $2(8.00)$ & $1(4.00)$ & $1(4.00)$ & $1(4.00)$ & $5(20.00)$ \\
\hline Total & $\mathbf{1 3 ( 5 2 )}$ & $\mathbf{2 ( 8 )}$ & $\mathbf{8 ( 3 2 )}$ & $\mathbf{4 ( 1 6 )}$ & $\mathbf{2 7}$ \\
\hline
\end{tabular}

Table5. Prevalence of different ectoparasitespecies in captured rats.

\begin{tabular}{|l|l|l|}
\hline Ctoparasits species & $\begin{array}{l}\text { Number and prevalence }(\%) \\
\text { ectoparasites }\left(\mathbf{N}_{\mathbf{1}}=\mathbf{2 7}\right)\end{array}$ & $\begin{array}{l}\text { Number and of }(\%) \text { rats } \\
\left.\text { infested( } \mathbf{N}_{\mathbf{2}}=\mathbf{2 0}\right)\end{array}$ \\
\hline Haemaphysalis spp & $9(33.33)$ & $9(45.00)$ \\
\hline Rhipicephalus sanguineus & $4(14.80)$ & $3(15.00)$ \\
\hline Xenopsylla cheopis & $2(7.40)$ & $1(5.00)$ \\
\hline Dermanyssus spp & $4(14.81)$ & $2(10.00)$ \\
\hline Polyplax spp & $8(29.63)$ & $5(25.00)$ \\
\hline TOTAL & $\mathbf{2 7}$ & $\mathbf{2 0}(\mathbf{8 0 . 0 0})$ \\
\hline
\end{tabular}

$N_{I}=$ Total ectoparasite encountered .

$\mathrm{N}_{2}=$ Total number of rats infested.

Table6. Prevalence of haemoparasite in captured rats.

\begin{tabular}{|c|c|c|c|c|}
\hline Haemoparasites & Number of rats infected & Prevalence (\%) & Mean abundance & Men intensity \\
\hline Plasmodium Spp & 3 & 12 & 0.12 & 0.15 \\
\hline Trypanosome spp & 1 & 4 & 00.04 & 0.05 \\
\hline Total & $\mathbf{4}$ & $\mathbf{1 6}$ & $\mathbf{0 . 1 6}$ & $\mathbf{0 . 2}$ \\
\hline
\end{tabular}




\section{REFERENCES}

[1] Barnett,S. and Anthony (2002). The Story of Rats: Their Impact on Us, and Our Impact on Them, Allen \&Unwin, Crows Nest, NSW, pp 202.

[2] Batters by, S.A., Parsons R. and Webster J.P. (2002).Urban rat infestations and the risk to public health. Journal of Environmental Healtth Research, 1(2): 4-12.

[3] Bonner, P.C., Schmidt, W.P., Belmain S.R., Oshin B., Baglode D. and Borchet M., (2007). Poor housing quality increases risk of rodent infestation and lassa fever in refugee camp. Am. J. Trop. Med. Hyg., 77: 169-175.

[4] Davis S., Calvet E. and Leirs H.,( 2005). Fluctuating rodent population and the risk to human from rodent bornezoonoses. Vector Borne and Zoonotic Diseases, 5(4): 305-314.

[5] Mafiana, C.F., Osho B.M. and Sam-Wobo S 1997). Gastrointestinal helminth parasites of the black rat (Rattusrattus) in Abeokuta, Nigeria. J. Helminthol., 71: 217-220.

[6] M banong, W.F., Nock I.H. and Ezealor A.U., (2002). A survey of ecto- and endoparasites of murid rats (Rodentia) in Samaru, Zaria, Nigeria. Journal of Tropical Biosciences, 2(1): 106-112.

[7] Meerburg, B. G., Singleton GR, Kijlstra A (2009). "Rodent-borne diseases and their risks for public health". Crit Rev Microbiol 35 (3): pp 221-70.

[8] Ministry of Health, (2007). Lassa fever cases on the increase. Quarterly Epidemiological Bullettin, Jos, Nigeria.

[9] Okeke, J.J., Ikegbunam, N.M., Umeaniebue, A.C., Ezeonyejiaku , D.C. and Ezeadila, J.O. (2013). Journal of Natural Sciences Research 3(2): 235-241.

[10] Olaseha, I.O., Sridhar, M.K.C., Obiako, P.C. and Oladapo, A. (1994). Rat infestation in urban and rural areas in Nigeria. Public health implications.J.Roy.Soc.Promo.Hlth.114(6): 300-303.

[11] Olubunmi, A. O. (2013). Parasites of Man and Animals.1st Edition, Concept Publications Ltd.Lagos, Nigeria.pp.576-579.

[12] Opara, M. N. and Fagbemi, B. O. (2008).Hematological and plasma biochemistry of the adult wild African Grasscutter (Thryonomysswinderianus): A zoonosis factor in the tropical humidrain forest of South east Nigeria. Ann. N. Y. Acad. Sci., 1149: $394-397$

[13] Pini, N., Levis S., CalseronG.,Barques R.M. and Enrina D.(2003) Hantavirus infection in humans and rodents in Northwestern Argentina. Emerging Infectious Diseases, 7: 116- 123.

[14] Soulsby, E. J. (1982). Helminthes, Arthropods and Protozoa of domesticated animals. 7th Edition, Bailliere Tindal, London. Pp. 367 - 703

[15] Stojcevic, D., Mihaljevic Z. and Marinculic A., (2004).Parasitological survey of rats in rural regions of Croatia. Vet. Med.-Cech, 49(3): 70-74.

[16] W.H.O. (1991).Basic laboratory methods in medical parasitology, Geneva. Pp 39 - 90. 